\title{
Use of satellite images to characterize the spatio-temporal dynamics of primary productivity in hotspots of endemic Iberian butterflies
}

\author{
Pedro Aragón ${ }^{\mathrm{a}, *}$, David Sánchez-Fernández ${ }^{\mathrm{b}, \mathrm{c}}$, Carlos Hernando ${ }^{\mathrm{a}}$ \\ ${ }^{a}$ Department of Biogeography and Global Change, Museo Nacional de Ciencias Naturales, CSIC (MNCN-CSIC), José Gutiérrez Abascal 2, 28006 Madrid, Spain \\ ${ }^{\mathrm{b}}$ Instituto de Ciencias Ambientales, Universidad de Castilla-La Mancha, Campus Tecnológico de la Fábrica de Armas, 45071 Toledo, Spain

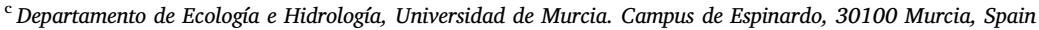

\section{A R T I C L E I N F O}

\section{Keywords:}

Enhanced vegetation index (EVI)

Environmental change

Iberian Peninsula

Land cover

Lepidoptera

Primary productivity

\begin{abstract}
A B S T R A C T
The Iberian Peninsula is one of the European regions with the highest number of endemic species. Therefore, it is imperative to identify species populations potentially affected by variations in ecosystem functioning. Since the emergence of data processed from satellites, the possibility of carrying out studies covering both a spatial and temporal dimension has increased, providing more comprehensive information about species population dynamics and ecosystems. Primary productivity is a crucial parameter for understanding ecosystem function and services because it is the basis of the trophic chain. This study examines the spatiotemporal variation in primary productivity over a 14-year temporal series (2000-2013) through the enhanced vegetation index (EVI). We focused on the hotspots of endemic diurnal butterflies in the Iberian Peninsula and obtained data on the primary productivity dynamics at these locations as indicators to optimize further conservation efforts. Within these hotspots, statistically significant yet spatially irregular trends were found at localized sites, mostly in mountain systems (the Cantabrian Mountains, Iberian System, Sierra de Guadarrama and Sierra Nevada). At $60 \%$ of these sites, primary productivity significantly decreased. Two endemic species, the Sierra Nevada blue (Polyommatus golgus) and the Puerto del Lobo butterfly (Agriades zullichi), which are classified by the International Union for Nature Conservation (IUCN) as "Vulnerable" and "Endangered", respectively, are present in localities where primary productivity showed a marked decline despite being within the Natura 2000 Network. The procedures developed here, which are based on consistent temporal trends of primary productivity, can serve as a tool to detect among biodiversity hotspots those locations where environmental change is unequivocal and hence further monitoring is needed.
\end{abstract}

\section{Introduction}

In the last two centuries, environmental changes in almost every region of the planet have occurred through anthropogenic activity, affecting biodiversity and causing changes to ecosystem function and services (Purvis and Hector, 2000; Zalasiewicz et al., 2011). All these changes have led to an increase in species extinction rates, to such an extent that the loss of diversity has become one of the main environmental challenges of our time (Cardinale et al., 2012). Especially sensitive species are those that are already in danger, are rare and/or have a decreasing or limited distribution (McKee et al., 2004; Brook et al., 2008; Aubad et al., 2010; Cardinale et al., 2012).

In the current context of global change, follow-up studies of the factors involved in these changes are especially important in trying to mitigate possible negative impacts. These factors are both abiotic and biotic, acting either separately or through interactions and synergies between them (Vitousek, 1994; Dukes and Mooney, 1999; Rouifed et al., 2010). Changes can be studied from a global scale to more local scales and from a geological time scale to shorter ecological time scales (e.g., the past few decades) in which society can perceive such changes directly (Wilbanks and Kates, 1999). It has been argued that variations in abiotic factors (e.g., climate change) have a greater impact at large scales (Pearson and Dawson, 2003) and that biotic factors can even reverse their spatio-temporal dynamics depending on the time frame and spatial scale considered (Piao et al., 2011; Wang et al., 2011; Gao et al., 2012a,b; Aragón et al., 2015). Over the past several decades, analyses of spatio-temporal trends in a global change context have often only considered specific abiotic variables, such as temperature or precipitation, because data on these variables were the easiest to obtain. However, primary productivity (PP) is a parameter of overwhelming

\footnotetext{
* Corresponding author.

E-mail address: paragon@mncn.csic.es (P. Aragón).
} 
importance in terms of the underlying processes of global change because it represents the most basal level of the trophic chain. PP reflects the entry and fixation of atmospheric carbon into ecosystems by plants, and all the trophic relationships in ecosystems depend on it through the transfer of this carbon to other trophic levels (Costanza et al., 2007; Richmond et al., 2007). Thus, significant changes in PP at short temporal scales could lead to strong changes in the structure and functioning of ecosystems and ultimately to the conservation of species.

The increase in the quality and precision of satellite images has become unprecedented over the last decade, which has allowed the determination of the distribution of vegetation and PP and the development of vegetation indices to examine trends at different spatiotemporal scales (Kogan, 1995; Prince and Goward, 1995; Clark et al., 2001; Running et al., 2004; Turner et al., 2005). However, recent reviews on the subject have argued that the use of satellite images for conservation purposes is still far from reaching its full potential (Cabello et al., 2012; Pettorelli et al., 2014; Rose et al., 2015). The vegetation indices generated from satellite imagery can be useful in detecting the indirect effects of climate change, impacts of ecological disturbances, or changes in land use (Hansen et al., 2000; Lucht et al., 2002; Aragón et al., 2015).

The integration of these approaches to optimize conservation efforts is especially important in those areas with higher biodiversity values, such as the Mediterranean basin. In particular, the Iberian Peninsula harbours $>50 \%$ of the endemic species in Europe (Myers et al., 2000; IUCN, 2017). Within the Iberian Peninsula itself, biodiversity is not evenly distributed but structured in hotspots. One of the most common strategies for the conservation of such areas with high biodiversity values is the establishment of protected areas, for which it is important to assess the effectiveness of the protection they provide to the species and habitats they comprise. However, most studies that evaluate the effectiveness of protected areas only address this issue from a spatial dimension, while spatio-temporal analyses in this regard are still scarce (Pressey et al., 2007). The few studies on this topic have noted that protected areas are designed with no consideration of the impacts of climate change. This is not a trivial issue because it has been shown that climate change may drive species out of reserves or cause local extinctions within reserves (Araújo et al., 2004, 2011) and that these impacts may affect functional groups differently (Aragón et al., 2010). On the other hand, while not directly focused on the protected area designs, remote sensing products through spatiotemporal series have been applied to assess the impact of environmental change, and/or ecosystem functioning, within and out of protected areas (e.g. Nagendra et al., 2013; Kachelriess et al., 2014; Regos et al., 2017). Besides, information on the spatial distribution of PP from remote sensing has been used to zoning potential protected areas although regardless of the temporal dimension (e.g. He et al., 2005). These environmental changes may be either indirect or independent effects of climate change and might cause concern when their trends are monotonic.

The general objective here is to use satellite imagery as a tool to identify among the hotspots of endemic butterflies belonging to the superfamily Papilionoidea in the Iberian Peninsula those for which further in situ monitoring is needed. For this purpose, we propose to examine PP trends over a temporal series (from 2000 to 2013) in areas that have been identified as hotspots of endemic butterflies in the Iberian Peninsula. Butterflies are holometabolous insects for which the majority of caterpillars are herb feeders (Mattson and Addy, 1975; Settele et al., 2009). Most caterpillars of the Iberian species belonging to the superfamily Papilionoidea feed on green plants of the families Fabaceae, Poaceae, Cruciferae and Rosaceae (Table 1, García-Barros et al., 2013). Due to this herbivorous condition, species belonging to Papilionoidea depend directly on the PP in the ecosystems to maintain the viability of populations over time. Additionally, once we identified hotspots where PP was not stable over time, we explored which factors could be related to these trends. Here, we adopted the most common interpretation of system stability: the tendency to return to an equilibrium point after a displacement (DeAngelis, 1980). First, we examined whether these trends presented a spatial structure in the Iberian Peninsula. Then, we explored whether they were related to i) the degree of area protection, the land uses or the land use changes, or ii) temporal changes in temperature within a climatic change context.

\section{Materials and methods}

\subsection{Study area and species}

The Iberian Peninsula is located in the Palaearctic region in southern Europe. Following the Köppen-Geiger climatic classification (http://koeppen-geiger.vu-wien.ac.at/), temperate climates, with temperate summers and no dry season, dominate in the northern half of the region. In the southern half, the temperate climate has a dry and hot summer, and cold steppe predominates. There are other categories with a more restricted area of distribution, such as the mountain climate, which normally hosts an important number of endemic species.

This study focuses on those grid cells within the Iberian Peninsula (UTM of $10 \times 10 \mathrm{~km}$ ) that have been recently identified as hotspots of endemic diurnal butterflies, with 4-7 endemisms (see Rosso et al., 2018 for more details), which correspond to 71 cells (Fig. 1). These areas were identified by Rosso et al. (2018) based on an update of the faunistic data of the Atlas of the Diurnal Butterflies of the Iberian Peninsula and the Balearic Islands (García-Barros et al., 2004). Other thresholds above and below 71 grid cells generated hotspots with a similar geographic structure (Rosso et al., 2018).

The species that compose the hotspots and relevant related information are shown in Table 1. Of the 16 Iberian endemics considered, two endemic species of the Sierra Nevada are noteworthy (Table 1). These species are the "Puerto del Lobo" butterfly (Agriades zullichi) and the Sierra Nevada blue (Polyommatus golgus), whose threat categories according to the IUCN Red List (2017) are "Endangered" and "Vulnerable", respectively. On the other hand, there are three other species that have not been catalogued according to the IUCN (2017) and therefore also need follow-up. Most of these species are univoltine (i.e., species with one generation per year; Table 1) and therefore could be more susceptible to pervasive changes in PP than multivoltine species (i.e., species with several generations per year). That is, species having higher fitness/year might better recover from negative impacts from pervasive effects of monotonic environmental changes, thus reducing the probability of local extinctions.

\subsection{The enhanced vegetation index and other spatial variables}

For the grid cells identified as hotspots, in addition to PP, land use variables, such as the types of vegetation cover and land use, land use changes, and the percentage of protected area (the Natura 2000 network) in each grid were taken into account. For the estimation of PP, the enhanced vegetation index (EVI) was used, which is an improvement from the commonly used NDVI index (normalized difference vegetation index) because it minimizes the variation in the canopy background and maintains the sensitivity of the conditions of dense vegetation (Huete et al., 2002). Both indices are based on the near infrared and red bands and represent an integrative measure of photosynthetic activity and green biomass (Huete et al., 2002). Additionally, the EVI corrects for aerosol influences on the red band using the blue band (Huete et al., 2002). The EVI values are obtained from MODIS satellite images available on NASA's digital platform NASA-LP DAAC (MOD13A2, https://lpdaac.usgs.gov/). The initial database corresponded to a temporal series that collects data for all months from 2000 to 2013 at a $1-\mathrm{km}$ resolution. Subsequently, for each hotspot, the monthly averages from March to September were calculated and upscaled to the hotspot resolution. We excluded winter months because larval diapause in the Iberian Peninsula occurs mainly during this season (García-Barros et al., 2013). We also decided to exclude the 
Table 1

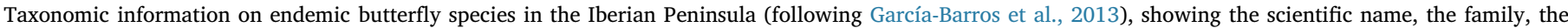

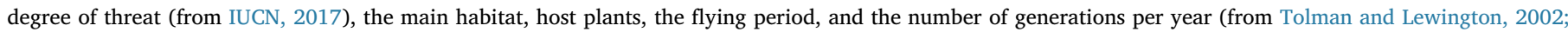
García-Barros et al., 2013). LC: Least concern, VU: Vulnerable, NT: Near threatened, EN: Endangered.

\begin{tabular}{|c|c|c|c|c|c|c|}
\hline Species & Family & Threat degree & Habitat & Host plants & Flying period & No. generations \\
\hline Euchloe bazae & Pieridae & LC & Meadow & Eruca vesicaria, Boleum asperum, Reseda phyteuma & May-September & Univoltine \\
\hline Lycaena bleusei & Lycaenidae & LC & Wet places & Rumex acetosa, $R$. acetosella, $R$. papillaris & April-September & Bivoltine \\
\hline Scolitantides panoptes & Lycaenidae & Not assessed & Dry and grassy places & $\begin{array}{l}\text { Thymus mastichina, T. vulgaris, T. zigys, T. orospedanus, } T . \\
\text { hyemalis }\end{array}$ & April-August & Univoltine \\
\hline Polyommatus golgus & Lycaenidae & VU & Exposed earrings & Anthyllis vulneraria & June-July & Univoltine \\
\hline Polyommatus nivescens & Lycaenidae & NT & Rocky land & A. vulneraria & April-August & Univoltine \\
\hline Polyommatus fulgens & Lycaenidae & LC & Exposed earrings & Onobrychis viciifolia & June-September & Bivoltine \\
\hline Polyommatus fabressei & Lycaenidae & LC & Ravines with bush & O. viciifolia & June-August & Univoltine \\
\hline Polyommatus violetae & Lycaenidae & LC & $\begin{array}{l}\text { Grassy places with } \\
\text { flowers }\end{array}$ & O. viciifolia & June-August & Univoltine \\
\hline Lysandra caelestissima & Lycaenidae & LC & Meadow & Hippocrepis comosa & June-August & Univoltine \\
\hline Aricia morronensis & Lycaenidae & LC & Rocky land & $\begin{array}{l}\text { Erodium glandulosum, E. foetidum, E. carvifolium, E. } \\
\text { cazorlanum, E. daucoides }\end{array}$ & May-September & Univoltine \\
\hline Kretania hesperica & Lycaenidae & Not assessed & Shrub areas & Astragalus alopecuroides, A. turolensis, A. nevadensis & May-August & Univoltine \\
\hline Agriades zullichi & Lycaenidae & EN & Shrub areas & Androsace vitaliana subsp. assoana & June-September & Univoltine \\
\hline Coenonympha glycerion & Nymphalidae & Not assessed & Shrub areas & Poa spp. & June-August & Univoltine \\
\hline Erebia hispania & Nymphalidae & LC & Exposed earrings & Festuca spp., Poa spp. & July-August & Univoltine \\
\hline Erebia zapateri & Nymphalidae & LC & $\begin{array}{l}\text { Glades in forests and } \\
\text { valleys }\end{array}$ & Nardus stricta, Festuca & July-September & Univoltine \\
\hline Erebia palarica & Nymphalidae & LC & $\begin{array}{l}\text { Glades in forests and } \\
\text { valleys }\end{array}$ & Festuca spp. & June-August & Univoltine \\
\hline
\end{tabular}

autumn period because our hotspots are located in mountain systems (see Section 3), where the inactivity period for caterpillars may begin earlier. Thus, the EVI values were single data points for each year and for each $10 \times 10 \mathrm{~km}$ grid associated with the hotspots.

Land cover data for the years 2000, 2006 and 2012 for the Iberian Peninsula were obtained from the CORINE land cover database (www. eea.europa.eu), which classifies soil types into 12 different categories in the 71 hotspots studied here. To simplify the subsequent statistical analyses, the map was reclassified by grouping functional categories based on the canopy density and height of the vegetation cover. Maps showing four functional categories of vegetation cover types were obtained: 1) trees, 2) bushes, 3) pastures and non-tree cropland, and 4) remaining minor land cover types (e.g., bare ground). The fourth category was excluded from subsequent analyses because there were only two cases. We also obtained two variables of land cover changes with regard to our aggregation of land cover types from 2000 to 2006 and

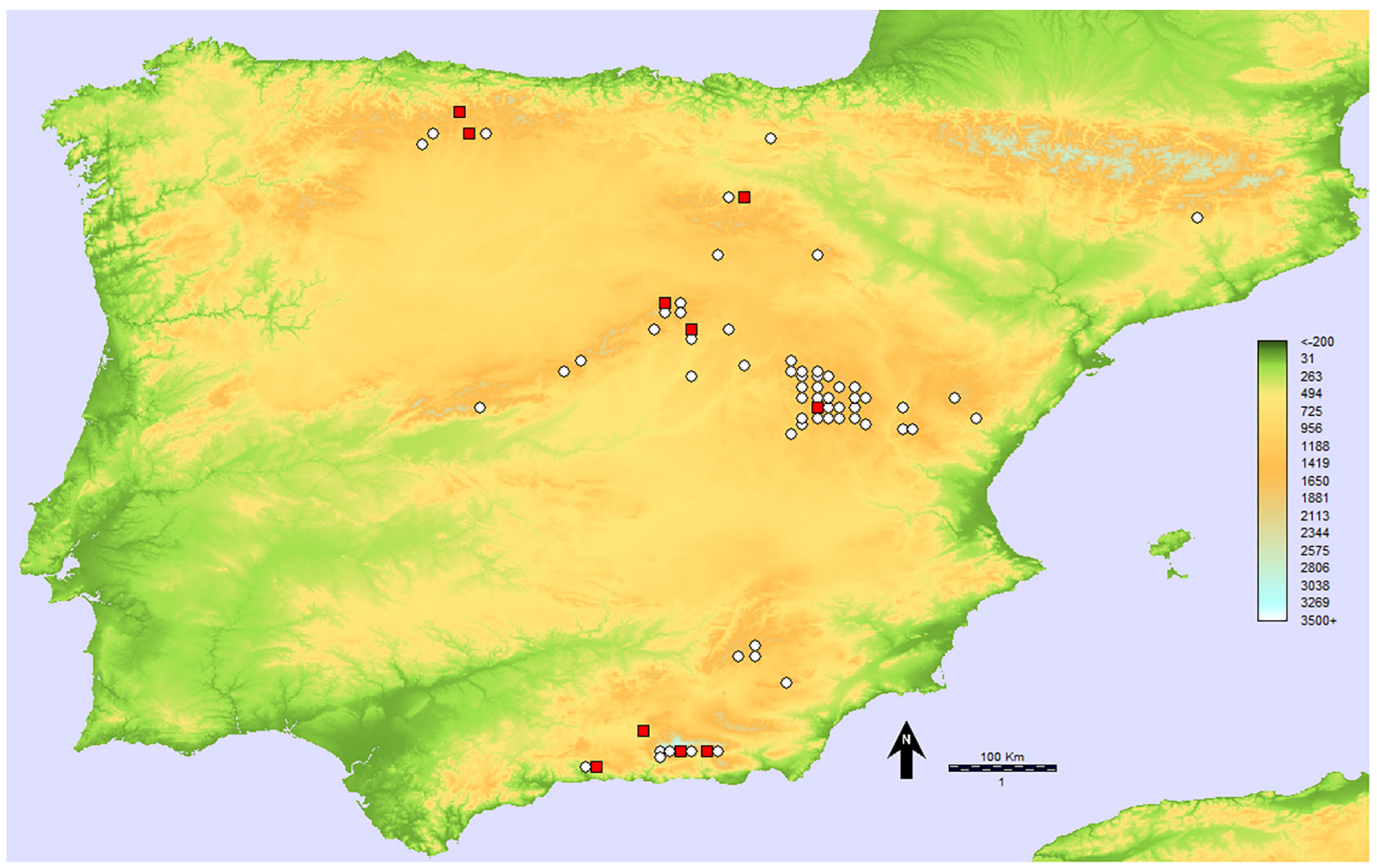

Fig. 1. Topographic map of the Iberian Peninsula showing the 71 endemic butterfly hotspots with the highest richness values (4-7 species). Red squares denote those hotspots where the temporal trends of the enhanced vegetation index (EVI) were statistically significant. The coloured bar denotes increasing altitude. 
from 2006 to 2012, and, finally, we kept only that of the first period of change because there were no substantial changes between 2006 and 2012 for our 71 hotspots.

The vector map of the Natura 2000 Network (hereafter N2000) was obtained from the website of the Ministry of Agriculture, Fisheries, Food and Environment (www.mapama.gob.es, MAPAMA). The N2000 is an integrated network of protected areas within all the countries of the European Union that is regulated by the Birds Directive (Directive 2009/147/EC of the European Parliament and of the Council) and by the Habitats Directive (Directive 92/43/EEC Council), which has led to the so-called Special Protection Areas for Birds (SPAs) and Special Areas for Conservation (SACs), respectively.

Finally, we obtained and processed time series data on the land surface temperature from MODIS satellite images available on NASA's digital platform NASA-LP DAAC (MOD11A2, https://lpdaac.usgs.gov/) at the same spatial resolution $(1 \mathrm{~km})$ and the same temporal coverage (2000-2013) as the EVI. We selected the MODIS product since it has the highest agreement with air temperature in comparison with other satellite-based temperature measurements (Urban et al., 2013). The temporal resolution of the land surface temperatures was an 8-day period for each pixel, which was averaged to encompass the activity period of the study species (spring and summer).

\subsection{Statistical analysis}

\subsubsection{Spatio-temporal trends in the EVI}

For each of the 71 hotspots, simple linear regressions were performed (Quinn and Keough, 2002), with the EVI being the dependent variable and year being the explanatory variable. The objective of these analyses was to examine the temporal variation in PP (i.e. to determine whether it has remained stable or has increased or decreased monotonically) throughout the temporal series under study, between 2000 and 2013. We also examined the spatial autocorrelation among the $r$ coefficients previously obtained from each of the abovementioned simple regressions to evaluate their similarity as a function of the proximity of hotspots. This procedure allows the extent to which the magnitude and direction of the EVI trends reflect spatial structure in the Iberian Peninsula to be inferred. To do so, correlograms of Moran's index $(I)$ were obtained, in which the significance of each distance class was estimated by means of 200 permutations. To obtain the correlograms, the spatial analysis program "Spatial Analysis in Macroecology" (SAM, Rangel et al., 2010) was used. Statistical significance in one or more of the distance classes indicates that the EVI-year relationships are not spatially independent.

Finally, as an additional test to collate with the EVI trend in each single hotspot, we performed another regression including the whole dataset with the 71 hotspots to examine whether a general temporal trend existed for the period 2000-2013.

\subsubsection{Testing for potential relationships between EVI trends and land cover types and area protection}

A general linear model (GLM) was carried out to test for potential relationships between the temporal tendencies of the EVI in the hotspots and the land cover types in the year 2006 and the degree of protection of the hotspots. We used the year 2006 for the land cover classes because it falls in the middle of our temporal series. For this analysis, the dependent variable used was the correlation coefficient $r$, which was previously obtained from each of the simple aforementioned regressions of the EVI. The explanatory variables were one categorical factor with three levels expressing the reclassified land cover (trees, shrubs, and grass or non-tree crops) and the percentage of overlap of each grid cell with the N2000 map (hereafter \%N2000). The initial full model included the interaction between land cover type and N2000, and the final model was obtained by backward stepwise selection (Quinn and Keough, 2002). An additional GLM analysis was performed excluding those grid cells where land cover changes occurred from
2000 to 2006 to avoid potential noise, if any, due to land use changes.

Further analyses were also carried out exclusively for those cases in which significant trends were found in the variation of the EVI over time (see the Section 3), that is, using the $r$ statistic as a dependent variable but restricting the analysis to the hotspots where the simple regressions of the EVI with respect to the variable "years" was significant. We initially intended to carry out the GLM analysis in the same way as when all the hotspots were considered. However, the number of hotspots in which the EVI trend was significant turned out to be small (see Section 3). Thus, for hotspots with a significant EVI trend, analyses were performed separately for each of the two explanatory variables because the number of degrees of freedom was too small. The distribution of residuals from these simple regressions differed from a normal distribution, and nonparametric analyses were therefore performed. Thus, to examine the association between the $r$ statistic and the independent variables, the Kruskal-Wallis test and a Spearman correlation analysis (Quinn and Keough, 2002) were performed for the explanatory variables land cover and $\%$ N2000, respectively.

\subsubsection{Testing for potential relationships in the temporal dimension}

For each of the hotspots with significant temporal EVI trends, we also examined potential relationships in the temporal dimension and in the context of climate change. First, we performed linear regressions between the time series of land surface temperatures and years to examine whether there was an increase in temperature in each of these hotspots. Then, we performed linear regressions between the time series of EVI and the time series of temperature at the same resolution and temporal coverage.

\section{Results}

Most of the endemic diurnal butterfly hotspots of the Iberian Peninsula were found at high altitudes (Fig. 1). We found 10 hotspots showing a significant temporal trend in the EVI over the 14 years of study (Table 2, Figs. 2 and 3). These sites are all located in mountain systems (the Cantabrian Mountains, Iberian System, Sierra de Guadarrama and Sierra Nevada, Fig. 1).

In these 10 hotspots, the patterns were not general, as there were negative trends in six of the hotspots (Table 2; Fig. 2), while in the remaining four hotspots, the EVI increased over the entire temporal series (Table 2; Fig. 3), and the explained variation ranged from $29 \%$ to $77 \%$.

The correlogram of Moran's I showed that there was no spatial autocorrelation in the value of the coefficient $r$ from the correlations between the EVI and the different years. The correlogram indicates that the spatial autocorrelation was not significant for any distance class $(P>0.1$ in all cases, Fig. S1 in Appendix 1). Thus, the 71 hotspots are spatially independent in terms of the magnitude and direction of the temporal pattern of the EVI. In this sense, sources of type I error, if any,

Table 2

Results from the Pearson correlation analysis for those butterfly hotspots where the temporal trends of the enhanced vegetation index (EVI) were statistically significant. Locations are ordered from north to south. The sign of the coefficient $r$ denotes the direction of the temporal trend.

\begin{tabular}{lllllll}
\hline Coordinates & $r$ & Slope & $P$-value & $\% \mathrm{~N} 2000$ & Richness & Province \\
\hline$-5.324,43.075$ & -0.64 & -68.7 & 0.013 & $100 \%$ & 4 & León (1) \\
$-5.225,42.875$ & -0.69 & -49.3 & 0.005 & $81 \%$ & 4 & León (2) \\
$-2.625,42.275$ & 0.62 & 22.3 & 0.018 & $21 \%$ & 4 & La Rioja \\
$-3.375,41.275$ & -0.88 & -52.3 & 0.00003 & $31 \%$ & 7 & Segovia \\
$-3.125,41.025$ & 0.59 & 16.1 & 0.026 & $18 \%$ & 4 & Guadalajara \\
$-1.925,40.275$ & -0.64 & -28.1 & 0.014 & $100 \%$ & 5 & Cuenca \\
$-3.575,37.225$ & 0.56 & 42.4 & 0.037 & $87 \%$ & 4 & Granada (1) \\
$-3.225,37.025$ & -0.58 & -10.8 & 0.029 & $100 \%$ & 5 & Granada (2) \\
$-2.975,37.025$ & -0.54 & -28.1 & 0.047 & $100 \%$ & 6 & Almería \\
$-4.025,36.875$ & 0.61 & 26.0 & 0.021 & $77 \%$ & 4 & Málaga \\
\hline
\end{tabular}



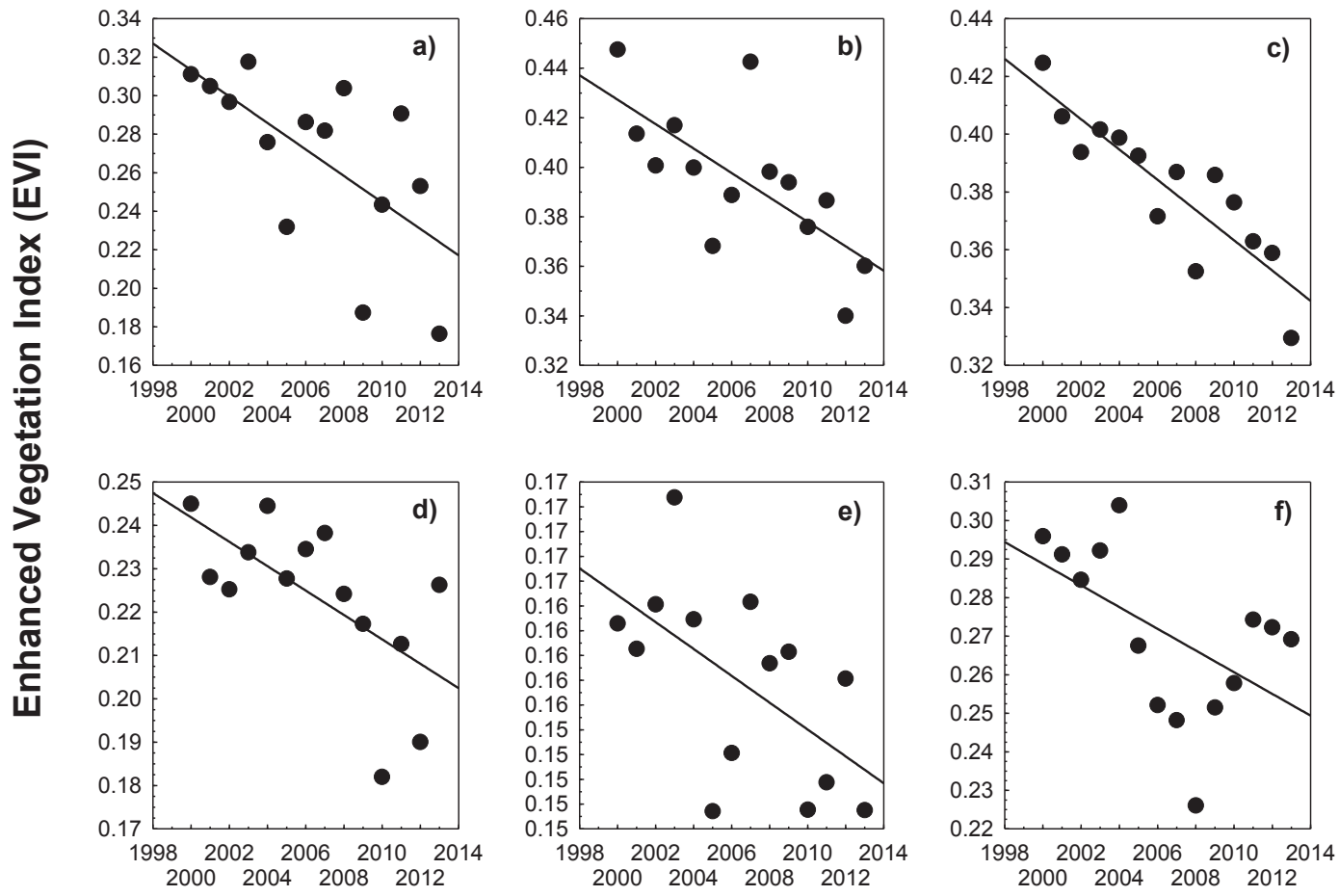

\section{Year}

Fig. 2. Statistically significant and negative temporal trends of the enhanced vegetation index (EVI) for the period 2000-2013 in grid cells of endemic butterfly hotspots in the Iberian Peninsula. a) The Cantabrian Mountains; province: León (1). b) The Cantabrian Mountains; province: León (2). c) Central System; province: Segovia. d) Iberian System; province: Cuenca. e) Betic System; province: Granada (2). f) Betic System; province: Almería. See Table 2 and Fig. 1 for more details.

cannot be due to the spatial dependence among cases, and hence it is not necessary to correct the significance values. In addition, the visual evaluation of these 10 significant regressions revealed that there were no outliers at the extremes of the temporal series that could be spuriously affecting the correlations (Figs. 2 and 3). The significant regressions will always represent the lowest $P$ value of the 71 cases. Finally, when analysing the whole dataset containing all 71 hotspots, we found no significant temporal trend (see Appendix 2), which is compatible with the heterogeneous tendencies at the grid level that might be counteracting one another.

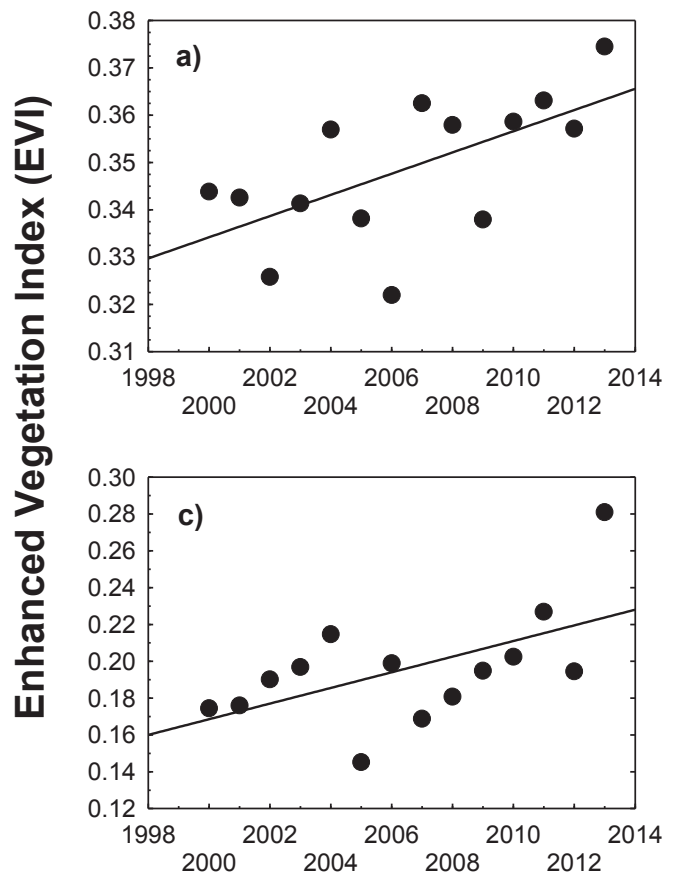

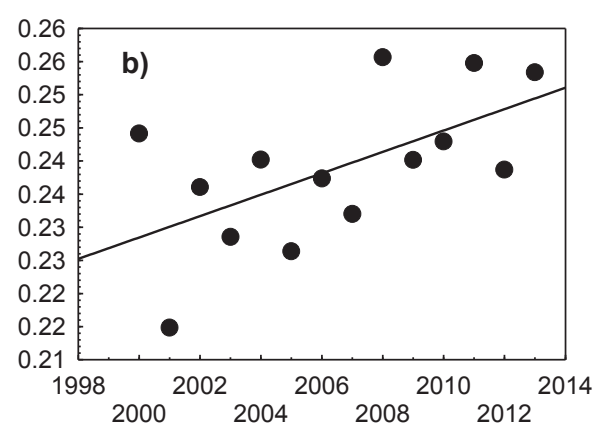

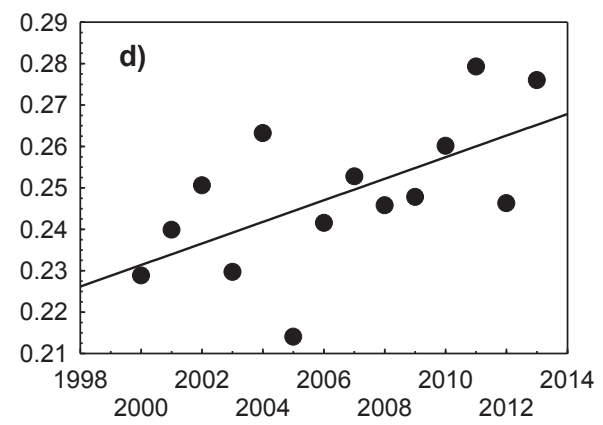

Fig. 3. Statistically significant and positive temporal trends of the enhanced vegetation index (EVI) for the period 2000-2013 in grid cells of endemic butterfly hotspots in the Iberian Peninsula. a) Iberian System; province: La Rioja. b) Central System; province: Guadalajara. c) Betic System; province: Granada (1). d) Betic System; province: Málaga. See Table 2 and Fig. 1 for more details.

\section{Year}


The percentage of the area covered by the N2000 is shown for the 10 hotspots with a significant EVI trend in Table 2. Interestingly, most of the hotspots showing significant EVI trends have extensive N2000 coverage ( $>77 \%$ in 7 out of the 10 hotspots, Table 2). However, although the N2000 coverage was highest in the Sierra Nevada (southeast Iberia), we found a hotspot at that location associated with a negative EVI trend. In addition, this hotspot harbours A. zullichi and $P$. golgus (two of the most threatened endemic diurnal butterfly species in the Iberian Peninsula). The N2000 coverage was low for the three significant hotspots of La Rioja (Iberian System), Segovia (Guadarrama Mountains) and Guadalajara ( $<32 \%$, Table 2$)$. It should be noted that although the hotspot located in the Guadarrama Mountains shows the highest butterfly richness, it is also the one with the lowest N2000 coverage (Table 2).

Once the trends and directions of the EVI for the 71 grid cells associated with the hotspots were obtained, GLM analyses were carried out to examine the potential influential factors. The final GLM including all the hotspots for the year 2006 did not retain the type of land cover, $\% \mathrm{~N} 2000$, or the interaction between these variables after backward stepwise selection $(F<2.79, P>0.05$ in all cases through backward elimination). The GLM to exclude those grid cells where land cover changes were detected, the results remained similar $(F<1.92$, $P>0.05$ in all cases through backward elimination). In all parametric analyses, the residuals of the models presented a distribution that did not differ significantly from the normal distribution, and variances were homogeneous.

Similarly, when the analyses were limited to only the 10 hotspots with a significant EVI trend over time, no significant Spearman correlations were found between the $r$ statistic and the $\% \mathrm{~N} 2000$ (Spearman correlation coefficient rho: $-0.41, P>0.05$ ). Similarly, there were no significant differences among the three major land cover classes (Kruskal-Wallis $H=2.50, P>0.28$ ).

Finally, despite the tendency of increase in the land surface temperature in these 10 hotspots (Appendix 3), none of the temporal trends were statistically significant $\left(F_{1,12}>4.16, R<0.50, P>0.05\right.$ in all cases). In addition, there were no significant relationships between the time series of the EVI and the time series of the land surface temperature ( $\mathrm{r}$ range: $-0.37-0.08, P>0.05$ in all cases), except for one case of marginal significance $(r=-0.54, P=0.043)$.

\section{Discussion}

In this study, we examined the temporal variation in PP over a temporal series of more than a decade in areas of special interest in the Iberian Peninsula: the hotspots of diurnal lepidopteran endemism. We identified hotspots that showed a statistically significant temporal trend. In addition, we examined whether the general EVI trend in the Iberian Peninsula could be explained in terms of the spatial variation in land cover and land cover changes and the degree of area protection. Finally, we examined whether there was an influence of global warming on the observed temporal trends of the EVI using variables at the same grain and resolution. Overall, our results can be seen as indicators of locations of high conservation value in terms of endemic butterfly species where ecosystem functioning, assessed by monotonic PP changes, is not stable and hence further in situ monitoring is encouraged. Thus, the finer-resolution monitoring of the highlighted locations would help to better characterize the potential context-dependent consumer-resource relationships (e.g., Gutiérrez et al., 2016).

One of the most relevant general results of our study was that only 10 of the 71 hotspots considered in the study (14\%) showed a significant EVI trend. One possible explanation is that most of the hotspots in this study were found at a relatively high altitude, where several of the different components of anthropogenic global change (e.g., changes in land use or pollution) are likely to have less impact than at loweraltitude localities. This is consistent with the fact that there were no land cover changes from 2006 to 2012 in our 71 hotspots. Moreover, the average N2000 coverage at the hotspots with a significant temporal trend was $72 \%$ (Table 2), indicating that at many of these sites, land use is at least very restricted, and therefore the negative influence of land use change is lower at these sites in comparison to areas outside the N2000.

Another important result of this study is that within the 10 hotspots whose temporal EVI trend was significant, there was also variability in terms of the direction of the trend (negative in $60 \%$ of the hotspots and positive in the rest). Although our results did not identify the processes underlying the temporal patterns in the EVI trends, at least in the hotspots where there was a negative EVI trend, we can assume a negative impact on the species as a consequence (due to the decrease in food availability), yet for the positive temporal trends, the consequences are uncertain because of the inherent complexity of biotic interactions. The fact that the direction and significance of the temporal trends of the EVI in this study do not follow a general spatial pattern at the meso-scale level contrasts with the results of previous studies at much larger scales. At the global level and coarse scales, it seems that $\mathrm{PP}$ is increasing as a result of the impacts of different components of global change, such as global warming, the quantity of available carbon in the atmosphere, and the increase in fertilizer use worldwide (e.g., Nemani et al., 2003; Mao et al., 2012; Eastman et al., 2013). However, studies on smaller scales show that the direction of the trend often varies because PP may be decreasing not only because of global change but also because of other local parameters that only become apparent at smaller scales (Field et al., 1995; DeLucía et al., 1999; Schröter et al., 2005). For example, it has been shown that the temporal trends of PP estimated through the NDVI can change (or even reverse) depending on the spatial scale (Gao et al., 2012a, b) and the temporal series (Piao et al., 2011; Wang et al., 2011). Therefore, a very marked large-scale trend may not be detected at a smaller scale or may even show the totally opposite pattern and may be influenced by local or regional factors that lose their effect or become undetectable when the study is conducted at a larger scale (McGill, 2010).

According to the IUCN classification (2017), some of the endemic lepidopterans of the Iberian Peninsula considered in this study are threatened and are sometimes found in grid cells with significant trends. Especially striking is the case of one grid cell (coordinates $-3.225,37.025$ ) located in the Sierra Nevada (Table 2), where three species under some degree of threat occur, $P$. nivescens, $P$. golgus and $A$. zullichi, and the trend of PP is markedly negative (Fig. 2e). It should also be noted that among the hotspots with a significantly negative trend, we find the hotspot with the highest richness of endemic species. It is located in the Sierra de Guadarrama, while the proportion of N2000 cover shows one of the lowest values (Segovia, coordinates -3.375 , 41.275, Table 2, Fig. 2c). This is not an unexpected result because the design of the $\mathrm{N} 2000$ is not explicitly based on the presence of butterfly endemisms (Rosso et al., 2018), and it has been previously found that Iberian butterfly endemisms are not well represented in the N2000 (Romo et al., 2007). Furthermore, it has been shown that butterfly richness is not necessarily related to the richness of other species (Gutiérrez and Menéndez, 2007). Both cases (Sierra Nevada and de Guadarrama) deserve special monitoring efforts, either because of the vulnerability of the species or because of the number of endemic species that these areas host.

The correlogram of Moran's I did not show significant autocorrelation in terms of the temporal EVI trends at any distance. In other words, the contiguous grid cells did not tend to be similar in terms of the magnitude or direction of the temporal EVI trend. This result likely indicates that the factors responsible for the temporal patterns of EVI act at a different scale from that addressed in our study. In fact, our analyses showed that there were also no effects of land cover type when considering both the 71 hotspots and only those with consistent EVI trends. Although the land cover variable was only analysed for the year 2006, we can rule out a strong influence of land use changes on the increase or decrease in EVI values over our entire time series. This is 
because the results remain similar after excluding those cases with land cover changes from 2000 to 2006. In addition, we found no land cover change between 2006 and 2012. Similarly, the percentage of N2000 overlapping each hotspot in our grid-cell system was not related to the corresponding EVI trend in the hotspot, either when considering the 71 hotspots or only those with significant trends. Moreover, within the 10 grid cells in which the EVI trend was significant, the influence of land use change would be more likely to be observed in those with a small percentage of area protected by the N2000 because changes in land use should be greater outside protected areas. However, it should be noted that in the 4 significant grid cells that are entirely covered by the network of protected spaces, the EVI trend consistently decreased (provinces of León, Cuenca, Granada and Almeria, Table 2). This fact also confirms that at these 4 sites, the downward EVI trend was not due to changes in land use. This finding also has an important implication: the type of protection provided by the N2000 does not necessarily ensure stability in PP.

Finally, our analysis of correlations between the EVI and temperature temporal series did not show any strong evidence of global warming as the cause of the temporal trends in the EVI. This result contrasts with previous findings of studies conducted at coarser scales and larger extents, in which temporal trends in PP were associated with increased temperature, which should be due to the abovementioned effects of differences in scale (McGill, 2010). Thus, a final consideration is that the results of the present study are compatible with the effects of global warming, land cover, and the proportion of protected areas at other scales or altitudes.

\section{Conclusions}

Several general conclusions can be drawn from the results obtained in this study. 1) Our results corroborate that very marked global or large-scale trends are not necessarily maintained and reproduced at smaller scales but can change according to the scale used in the study. 2) We did not find a link between the magnitude or direction of the primary production trend and the degree of protection or vegetation cover. 3) There was no spatial pattern in terms of an increase or decrease in primary production in these areas, although consistent trends were associated with mountainous systems. There are grid cells in which PP increases and others in which it decreases, which may be due to the idiosyncrasies of each site, the nature of which is difficult to detect without in situ monitoring at the same temporal scale as the satellite images analysed in this study. 4) This study shows that two threatened species in the study area, the Sierra Nevada blue ( $P$. golgus) and the "Puerto del Lobo" butterfly (A. zullichi), are present at sites where primary production showed a marked decline despite being within the Natura 2000 network. Therefore, in situ monitoring should focus on characterizing the dynamics of their populations in the Sierra Nevada and the underlying processes of these dynamics. 5) The protection offered by the Natura 2000 network does not always guarantee ecosystem stability because even in these protected areas, a parameter as important as primary productivity may change monotonically. 6) Future research at narrower scales than in our study should focus on the application of additional ecosystem functional attributes from remote sensing (Cabello et al., 2012; Arenas-Castro et al., 2018) to give further insights on the processes underlying the detected patterns and hence to better understand impacts on species of conservation value.

\section{Acknowledgements}

This study was supported by the projects NICHEAPPS (CGL201456416-P) granted to P.A., funded by the Spanish Ministry of Economy and Competitiveness (MINECO), and POII11-0277-5747, funded by the "Junta de Castilla-La Mancha". P.A. was supported by the MINECO Ramón y Cajal Program (RYC-2011-07670). DS-F was supported by two post-doctoral contracts funded by the University of Castilla-La Mancha and the University of Murcia. We thank three anonymous referees for helpful comments on the manuscript.

\section{Appendix A. Supplementary data}

Supplementary data to this article can be found online at https:// doi.org/10.1016/j.ecolind.2019.105449.

\section{References}

Aragón, P., Rodríguez, M.A., Olalla-Tárraga, M.A., Lobo, J.M., 2010. Predicted impact of climate change on threatened terrestrial vertebrates in central Spain highlights differences between endotherms and ectotherms. Anim. Conserv. 13, 363-1273.

Aragón, P., Sánchez-Fernández, D., Abellán, P., Varela, S., 2015. Effects of temporal bias on the assessment of an ecological perturbation: a case study of the Prestige oil spill. Environ. Res. Lett., 094006.

Araújo, M.B., Cabeza, M., Thuiller, W., Hannah, L., Williams, P.H., 2004. Would climate change drive species out of reserves? An assessment of existing reserve-selection methods. Glob. Change Biol. 10, 1618-1626.

Araújo, M.B., Alagador, D., Cabeza, M., Nogués-Bravo, D., Thuiller, 2011. Ecol. Lett. 14, 484-492.

Arenas-Castro, S., Gonçalves, J., Alves, P., Alcaraz-Segura, D., Honrado, J.P., 2018. Assessing the multi-scale predictive ability of ecosystem functional attributes for species distribution modelling. PLoS ONE 13, e0199292.

Aubad, J., Aragón, P., Rodríguez, M.A., 2010. Human access and landscape structure effects on Andean forest bird richness. Acta Oecol. 36, 396-402.

Brook, B.W., Sodhi, N.S., Bradshaw, C.J., 2008. Synergies among extinction drivers under global change. Trends Ecol. Evol. 23, 453-460.

Cabello, J., Fernández, N., Alcaraz-Segura, D., Oyonarte, C., Piñeiro, G., Altesor, A., Delibes, M., Paruelo, J.S., 2012. The ecosystem functioning dimension in conservation: insights from remote sensing. Biodivers. Conserv. 21, 3287-3305.

Cardinale, B.J., Emmett Duffy, J., Gonzalez, A., Hooper, D.U., Perrings, D., Venail, P., Narwani, A., Mace, G.M., Tilman, D., Wardle, D.A., Kinzig, A.P., Daily, G.C., Loreau, M., Grace, J.B., Larigauderie, A., Srivastava, D.S., Naeem, S., 2012. Biodiversity loss and its impact on humanity. Nature 486, 59-67.

Clark, D.A., Brown, S., Kicklighter, D.W., Chambers, J.Q., Thomlinson, J.R., Ni, J., 2001. Measuring net primary production in forests: concepts and field methods. Ecol. Appl. $11,356-370$.

Costanza, R., Fisher, B., Mulder, K., Liu, S., Christopher, T., 2007. Biodiversity and ecosystem services: a multi-scale empirical study of the relationship between species richness and net primary production. Ecol. Econ. 61, 478-491.

DeAngelis, D.L., 1980. Energy flow, nutrient cycling, and ecosystem resilience. Ecology $61,764-771$.

DeLucía, E.H., Hamilton, J.G., Naidu, S.L., Thomas, R.B., Andrews, J.A., Finzi, A., Schlesinger, W.H., 1999. Net primary production of a forest ecosystem with experimental CO2 enrichment. Science 284, 1177-1179.

Dukes, J.S., Mooney, H.A., 1999. Does global change increase the success of biological invaders? Trends Ecol. Evol. 14, 135-139.

Eastman, J.R., Sangermano, F., Machado, E.A., Rogan, J., Anyamba, A., 2013. Global trends in seasonality of normalized difference vegetation index (NDVI), 1982-2011. Remote Sens. 5, 4799-4818.

Field, C.B., Randerson, J.T., Malmström, C.M., 1995. Global net primary production: combining ecology and remote sensing. Remote Sens. Environ. 51, 74-88.

Gao, X., Li, S., Zhao, Z., Cai, Y., 2012a. Investigating spatial variation in the relationships between NDVI and environmental factors at multi-scales: a case study of Guizhou Karst Plateau, China. Remote Sensing 33, 2112-2129.

Gao, X., Huang, J., Li, S., Li, S., 2012b. Spatial pattern of non-stationarity and scaledependent relationships between NDVI and climatic factors-A case study in Qinghai-Tibet Plateau, China. Ecol. Ind. 20, 170-176.

García-Barros, E., Munguira, M.L., Martín Cano, J., Romo, H., García-Pereira, P., Maravalhas, E.S. (2004). Atlas de las Mariposas Diurnas de la Península Ibérica e Islas Baleares (Lepidoptera: Papilionoidea y Hesperioidea). Monografías S.E.A., Vol. 11. Zaragoza.

García-Barros, E., Munguira, M.L., Stefanescu, C., Moreno, V., 2013. Lepidoptera: papilionoidea. In: In: Ramos, M.A. (Ed.), Fauna Ibérica Vol. 37. CSICMuseo Nacional de Ciencias Naturales, Madrid, pp. 43-274.

Gutiérrez, D., Menéndez, R., 2007. Regional hotspots of butterfly diversity in a protected area: are they indicators of unique assemblages and areas with more species of conservation concern? Acta Oecol. 32, 301-311.

Gutiérrez, D., Vila, R., Wilson, R.J., 2016. Asymmetric constraints on limits to species ranges influence consumer resource richness over an environmental gradient. Glob. Ecol. Biogeogr. 25, 1477-1488.

Hansen, M.C., Defires, R.S., Townshend, J.R.G., Sohlberg, R., 2000. Global land cover classi. cation at $1 \mathrm{~km}$ spatial resolution using a classi. cation tree approach. Int. J. Remote Sens. 21, 1331-1364.

He, C., Zhang, Q., Li, Y., Li, X., Shi, P., 2005. Zoning grassland protection area using remote sensing and cellular automata modeling-A case study in Xilingol steppe grassland in northern China. J. Arid Environ. 63, 814-826.

Huete, A., Didan, K., Miura, T., Rodriguez, E.P., Gao, X., Ferreira, L.G., 2002. Overview of the radiometric and biophysical performance of the MODIS vegetation indices. Remote Sens. Environ. 83, 195-213.

IUCN (2017). The IUCN Red List of Threatened Species. Version 2017-2.

Kachelriess, D., Wegmann, M., Gollock, M., Pettorelli, N., 2014. The application of remote 
sensing for marine protected area management. Ecol. Ind. 36, 169-177.

Kogan, F.N., 1995. Application of vegetation index and brightness temperature for drought detection. Adv. Space Res. 15, 91-100.

Lucht, W., Prentice, I.C., Myneni, R.B., Sitch, S., Friedlingstein, P., Cramer, W., Bousquet, P., Buermann, W., Smith, B., 2002. Climatic control of the high-latitude vegetation greening trend and Pinatubo Effect. Science 296, 1687-1689.

Mao, J., Shi, X., Thornton, P.E., Piao, S., Wang, X., 2012. Causes of spring vegetation growth trends in the northern mid-high latitudes from1982 to 2004. Environ. Res. Lett. 7, 014010.

Mattson, W.J., Addy, N.D., 1975. Phytophagous insects as regulators of forest primary production. Science 190, 515-522.

McGill, B.J., 2010. Matters of scale. Science 328, 575-576.

McKee, J.K., Sciulli, P.W., Fooce, C.D., Waite, T.A., 2004. Forecasting global 846 biodi versity threats associated with human population growth. Biol. Conserv. 115, 161-164.

Myers, N., Mittermeier, R.A., Mittermeier, C.G., Fonseca, G.A.B., Kent, J., 2000. Biodiversity hotspots for conservation priorities. Nature 403, 853-858.

Nagendra, H., Lucas, R., Honrado, J.P., Jongman, R.H.G., Tarantino, C., Adamo, M., Mairota, P., 2013. Remote sensing for conservation monitoring: assessing protected areas, habitat extent, habitat condition, species diversity, and threats. Ecol. Ind. 33, 45-59.

Nemani, R.R., Keeling, C.D., Hashimoto, H., Jolly, W.M., Piper, S.C., Tucker, C.J., Running, S.W., 2003. Climate-driven increases in global terrestrial net primary production from 1982 to 1999. Science 300, 1560-1563.

Pearson, R.G., Dawson, T.P., 2003. Predicting the impacts of climate change on the distribution of species: are bioclimate envelope models useful? Glob. Ecol. Biogeogr. 12, 361-371.

Pettorelli, N., Laurance, W.F., O’Brien, T.G., Wegmann, M., Nagendra, H., Turner, W., 2014. Satellite remote sensing for applied ecologists: opportunities and challenges. J. Appl. Ecol. 51, 839-848.

Piao, S., et al., 2011. Evidence for a weakening relationship between interannual temperature variability and northern vegetation activity. Nat. Commun. 5, 5018.

Pressey, R.L., Cabeza, M., Watts, M.E., Cowling, R.M., Wilson, K.A., 2007. Conservation planning in a changing world. Trends Ecol. Evol. 22, 583-592.

Prince, S., Goward, S., 1995. Global Primary Production: A Remote Sensing Approach. J. Biogeogr. 22, 815-835.

Purvis, A., Hector, A., 2000. Getting the measure of biodiversity. Nature 405, 212-869.

Quinn, G.P., Keough, M.J., 2002. Experimental Design and Data Analysis for Biologists Cambridge University, UK.

Rangel, T.F.L.V.B., Diniz-Filho, J.A.F., Bini, L.M., 2010. SAM: a comprehensive application for Spatial Analysis in Macroecology. Ecography 33, 46-50.

Regos, A., Tapia, L., Gil-Carrera, A., Domínguez, J., 2017. Monitoring protected areas from space: a multi-temporal assessment using raptors as biodiversity surrogates. PLOS ONE 12, e0181769.

Richmond, A., Kaufmann, R.K., Myneni, R.B., 2007. Valuing ecosystem services: A shadow price for net primary production. Ecol. Econ. 64, 454-462.

Romo, H., Munguria, M.L., García-Barros, E., 2007. Area selection for the conservation of butterflies in the Iberian Peninsula and Balearic Islands. Anim. Biodivers. Conserv. 30 (1), 7-27.

Rose, R.A., et al., 2015. Ten ways remote sensing can contribute to conservation. Conserv. Biol. 29, 350-359.

Rosso, A., Aragón, P., Acevedo, F., Doadrio, I., García-Barros, E., Lobo, J.M., LópezMunguira, M., Monserrat, V.J., Palomo, J., Pleguezuelos, J.M., Romo, H., Triviño, V., Sánchez-Fernández, D., 2018. Effectiveness of the Natura 2000 network in protecting Iberian endemic fauna. Anim. Conserv. 21, 262-271.

Rouifed, S., Handa, I.T., David, J., Hättenschwiler, S., 2010. The importance of biotic factors in predicting global change effects on decomposition of temperate forest leaf litter. Oecologia 163, 247-256.

Running, S.W., Nemani, R.R., Heinsch, F.A., Zhao, M., Reeves, M., Hashimoto, H., 2004. A continuous satellite-derived measure of global terrestrial primary production. Bioscience 54, 547-560.

Schröter, D., Cramer, W., Leemans, R., Prentice, I.C., Araújo, M.B., Arnell, N.W., Anne, C., 2005. Ecosystem service supply and vulnerability to global change in Europe. Science 310, 1333-1337.

Settele, J., Shreeve, T., Konvicka, M., Van Dyck, H., 2009. Ecology of Butterflies in Europe. Cambridge University Press.

Tolman, T., Lewington, R., 2002. Guía de las Mariposas de España y Europa. Lynx Edicions.

Turner, D.P., Ritts, W.D., Cohen, W.B., Maeirsperger, T.K., Gower, S.T., Kirschbaum, A.A., Law, B.E., 2005. Site-level evaluation of satellite-based global terrestrial gross primary production and net primary production monitoring. Glob. Change Biol. 11, $666-684$.

Urban, M., Eberle, J., Hüttich, C., Schmullius, C., Herold, M., 2013. Comparison of satellite-derived land surface temperature and air temperature from meteorological stations on the pan-arctic scale. Remote Sensing 5, 2348-2367.

Vitousek, P.M., 1994. Beyond global warming: ecology and global change. Ecology 75, 1861-1876.

Wang, X., Piao, S., Ciais, P., Li, J., Friedlingstein, P., Koven, C., Chen, A., 2011. Spring temperature change and its implication in the change of vegetation growth in North America from 1982 to 2006. Proc. Natl. Acad. Sci. U.S.A. 108, 1240-1245.

Wilbanks, T.J., Kates, R.W., 1999. Global change in local places: how scale matters. Clim. Change 43, 601-628.

Zalasiewicz, J., Williams, M., Haywood, A., Ellis, M., 2011. The anthropocene: a new epoch of geological time? Philos. Transl. R. Soc. A 369, 835-841. 